\title{
El Software en la empresa: Análisis legal del Contrato de Escrow
}

\author{
Prof. José Francisco ESPINOZA CÉSPEDES
}

El mundo empresarial en constante vinculación con la sociedad necesariamente requiere interactuarcon el desarrollo e implementación de elementos inmateriales para lograr eficiencia en sus diversas actividades comerciales, industriales o de servicios. Por ejemplo, se utilizan diversos sistemas informáticos conectados a redes, se requieren elementos lógicos como el software en casi todas las etapas de la producción, la gestión y el desarrollo empresarial.

En el marco de la aplicación de los elementos lógicos como el software, en la vida empresarial surgen una serie hechos, actos y acciones que pueden afectar a la empresa, debido al nivel cada vez más interdependiente entre software y empresa.

El Perú constantemente se va incorporando más y más al mundo tecnológico a través de los Tratados de Libre Comercio - TLC, surgiendo una serie de relaciones empresariales de lo más variadas y desconocidas; en cada una de esas actividades la necesidad por el uso del software es cada más creciente, tanto a nivel de software de uso masivo como los sistemas operativos, procesadores de textos, hojas de cálculo, presentadores, bases de datos, etc., que permitan al sector empresarial el desarrollo de actividades cotidianas y comunes a todo su ámbito de competencia.

Las exigencias internacionales antes reseñadas también traen como consecuencia el desarrollo de un mercado del software especializado, es decir, el mercado de los elementos inmateriales de aplicación específica para cada sector empresarial, surgiendo de esta manera diversos software aplicativos que realizan tareas específicas para el control de calidad, control de plagas, control de pesos, control de medidas, verificación de estándares internacionales, cobranzas, contabilidad, pago de impuestos, pago de haberes, manejo de almacenes, manejo de grandes volúmenes de documentos con valor legal y sin valor legal, verificación de archivos de documentos tanto físicos como electrónicos, etc. 
"El (...) desarrollo de las Tecnologías de la Información y las Comunicaciones -TICs, en un marco de aumento del conocimiento en la sociedad, en un contexto donde se aprecia un incremento de las necesidades vinculadas con el desarrollo de mejores y más eficientes comunicaciones para la transmisión de datos e información [genera] una serie de problemas vinculados con diversas afectaciones a los sistemas y las tecnologías."

La competencia y especialidad de las empresas tanto nacionales como internacionales generan nuevas necesidades respecto del uso de diversos tipos de software con alto nivel de creación intelectual y por lo tanto, con gran capacidad para generar valor a las empresas donde se aplican. Por ejemplo, una empresa que debe atender un mercado típico de cerámicos debe cumplir con estándares de calidad respecto de la procedencia de la materia prima empleada, las pinturas utilizadas, los artesanos que participaron, etc. Exigencias que serían muy complicadas de cumplir de no existir intangibles aplicables a cada sector de la vida empresarial y de la producción en su conjunto.

Con la finalidad de controlar todos los procesos empresariales, desde el diseño, producción y puesta en venta de los bienes producidos se requiere el diseño de diversos tipos de software. Hay dos formas de producir el software requerido por las empresas: 1) La empresa contrata sus propios técnicos, informáticos e ingenieros de software, o 2) Se opta por contratar el servicio de terceros.

De optar por el último caso, es decir acudir a una empresa tercera que le desarrolle el software específico y necesario para el desarrollo de sus actividades empresariales, surge la necesidad de contar con un instrumento jurídico que le permita asegurar permanentemente el servicio del software diseñado e implementado para efectos específicos, que le permitan atender permanentemente las necesidades empresariales.

Para tal efecto, la respuesta jurídica se vincula con la necesidad de generar una relación contractual que facilite probar fehacientemente la existencia de una relación por la cual existe el compromiso de ambas partes por proteger el diseño, desarrollo, implementación y posteriores mantenimientos requeridos por el software aplicable exclusivamente a determinadas actividades empresariales.

Si recurrimos al Derecho Civil, podemos encontrar las reglas básicas y fundamentales de los contratos civiles, pero ninguno de los contratos previstos en el referido cuerpo legal satisfacen la necesidades empresariales derivadas de la interacción entre el Derecho y la Informática, para tal efecto debemos acudir

1 Espinoza Céspedes, José Francisco. El Derecho Informático Frente a la Contratación Pública Electrónica. Trabajo publicado en la Biblioteca Jurídica Virtual de la UNAM de México. En: http://biblio.juridicas.unam.mx/libros/6/2940/19.pdf. Revisada el 24-09-12. 
al Derecho Informático ${ }^{2}$, como rama nueva del Derecho que analiza, estudia y busca crear soluciones eficientes en torno al uso y aplicación de la informática y las Tecnologías en General en el contexto social, sobre todo en el ámbito empresarial.

El Derecho informático como rama novísima del Derecho propone la aplicación de diversas instituciones que permitan crear valor en las empresas con un adecuado nivel de respaldo y seguridad jurídica. Para efectos, de la aplicación y utilización de bienes inmateriales como el software plantea la creación de los contratos informáticos, que buscan lograr un equilibrio entre las partes contratantes a nivel de información técnica especializada derivada de los propios conceptos y conocimientos generados por el crecimiento, desarrollo y aplicación de la informática en todas las áreas de la sociedad.

Los contratos informáticos tienen la ventaja de crear valor a las relaciones entre proveedor y usuario (cliente), tanto a nivel de la transferencia de información técnica, capacitación, estudios preliminares, restricciones, garantías, cumplimiento de obligaciones específicas, pagos, derechos y obligaciones, etc.

Debido al desarrollo y crecimiento de las actividades empresariales dependientes de software cada vez más especializado, se requiere la aplicación de nuevos contratos empresariales que faciliten la actividad de los inversores y empresarios en general, para tal efecto, a fin de asegurar la permanente utilización de los elementos intangibles diseñados para actividades empresariales específicas proponemos la utilización intensiva de un nuevo tipo de contratos que se adapte a las nuevas exigencias y necesidades empresariales a inicios del siglo XXI, para tal efecto, consideramos de vital importancia el uso del Contrato de Escrow.

El contrato de Escrow, es un contrato atípico respecto de los contratos regulados por el Derecho Civil peruano a través del Código Civil de $1984^{3}$, por cuanto el referido contrato no se encuentra regulado, tal como sucede con el contrato de compraventa, el arrendamiento, etc.

Por sus particularidades el contrato de Escrow ${ }^{4}$ día a día se va consolidando como un contrato típico para el mundo empresarial del siglo XXI, que cada

2 Mayores referencias en: Espinoza Céspedes, José Francisco. Derecho Informático, Contratación Electrónica y Medidas de Seguridad. Lima. RAO. 2000.

3 Norma aprobada por Decreto Legislativo No 295, del 24 de julio de 1984, vigente desde el 14 de noviembre de 1984.

4 Al respecto es importante tener en cuenta que el "contrato de escrow, o también conocido como contrado de depósito del código fuente, podemos decir que se trata de una relación jurídica estrechamente relacionada con los contratos de desarrollo de programas informáticos, ya que se trata de establecer una medida garantista [para los productores de Software y para los usuarios]" En: ARIAS POU, María. Manual Práctico de Comercio Electrónico. Madrid. La Ley. 2006. p. 774. 
vez es más dependiente del uso de redes, computadoras, servidores, netbooks, notebooks, laptops, y diversos equipos físicos que por su propia naturaleza y especialidad requieren de determinado software para su funcionamiento.

Hoy en día el uso del software específico y de aplicación individual para las actividades industriales, extractivas, comerciales, de servicios, etc.; hacen que el software aplicativo sea de uso masivo y de necesidad fundamental para la supervivencia empresarial en un mundo tecnológico interconectado; en ese orden de ideas, el contrato de Escrow cobra real y efectiva vigencia para el desarrollo de las actividades que requieren del uso de elementos lógicos como el software tanto en medios físicos como electrónicos.

El software, por su naturaleza inmaterial faculta el funcionamiento de equipos y computadoras, está compuesto en su estructura interna entre otras componentes por el Código Fuente, es decir por el diseño y desarrollo lógico que permite poner en marcha los elementos físicos antes referidos. Es ese orden de ideas, es fácilmente deducible la gran importancia que adquiere el Código Fuente como estructura interna básica de todo desarrollo informático.

Si el Código Fuente no logra estar a plena disposición del empresario, adquirente de determinado desarrollo lógico (software), siempre existirá la posibilidad de una sería afectación a las diversas actividades económicas y empresariales del titular de los derechos de uso del software.

En un contexto de creciente utilización del software específico y aplicativo para las operaciones comerciales, productivas y empresariales en general, el aseguramiento de la plena utilización del software en el tiempo debe estar garantizado, dicha garantía la otorga el contrato de Escrow, mecanismo legal por el cual el desarrollador, programador o ingeniero de software procede a depositar ante un tercero el Código Fuente.

Por la importancia que adquiere el Código Fuente, podemos afirmar sin temor a equivocarnos que quien tenga acceso total e irrestricto al software y sobre todo a su estructura interna representada por el Código Fuente, tendría una posición dominante en su mercado, estando en condiciones de desarrollar políticas empresariales a largo plazo con la certeza de estar respaldado por el acceso a Código Fuentes de ocurrir problemas con el proveedor de software, gracias a la existencia de una relación contractual donde el objeto de contratación es el Código Fuente del correspondiente software como elemento inmaterial vital para la supervivencia en un mundo tecnológico en creciente desarrollo informático y electrónico. 
En ese sentido, a fin de evitar problemas empresariales por el uso del software, el Derecho Informático, como una rama novísima del Derecho propone, la redacción de los contratos de Escrow como solución eficiente para evitar los problemas derivados por la falta de uso o acceso al Código Fuente en las actividades empresariales y sociales en general.

El deposito del Código Fuente, en su correspondiente soporte material de almacenamiento tales como el CD, el DVD o el BluRay, ante un tercero que puede ser un Notario público, una empresa de almacenamiento de intangibles, empresas de seguridad de información, etc., garantiza que de ocurrir la salida del mercado del proveedor, desarrollador o empresa diseñadora, el adquirente del software tenga acceso irrestricto al Código Fuente, siempre respetando los derechos de autor del titular del mismo, a fin de estar en condiciones de realizar las modificaciones, adaptaciones, nuevas versiones, que le permitan seguir presentado el servicio de manera adecuada a sus clientes y proveedores, en vista que tiene asegurado el ingreso a la estructura interna del software, a fin de prever y levantar todas las contingencias relativas a la obsolescencia del software.

Como requisito fundamental en todo pacto de Escrow, surge la necesidad que el adquirente de la licencia de determinado software aplicativo pacte expresamente no solo el almacenamiento del elemento intangible ante el tercero (Notario o empresa de almacenamiento y seguridad), si no que deberá preverse expresamente una cláusula que faculte al adquirente a tener acceso a futuras versiones y actualizaciones del software materia de contratación a fin de prever la continuidad del servicio, tales acciones deben ser realizas como pacto complementario al acceso del Código Fuente en momentos en que el proveedor del servicio deje de operar en el mercado, sea por fusión, absorción, disolución, liquidación o cualquier otra afectación empresarial.

El contrato de Escrow, permite que se señale contrate expresamente quien o quienes son los facultados para acceder al Código Fuente, debiendo existir cláusula sobre los derechos patrimoniales derivados de la utilización del software, así como mecanismos taxativos de transferencia de la defensa de los derechos morales inherentes a los desarrolladores, e ingenieros que participan en la creación e implementación de los intangibles.

En el sistema jurídico inglés o del commom law existe la figura especializada, el Escrow Agente, es decir la personal encargada del almacenamiento del Código fuente para lo cual dicha persona debe cumplir con una serie de requisitos y estándares de seguridad que impidan cualquier afectación al elemento inmaterial (software) que se le encargue para su correspondiente almacenamiento o resguardo. 
En nuestro sistema jurídico vinculado con el sistema romano germánico, los que requieran el servicio deberán pactar el contrato de Escrow ${ }^{5}$ con un Notario público o con una empresa de servicios informáticos que cuente con los equipos y sistemas necesarios que permitan el almacenamiento del Código Fuente con total seguridad tanto a nivel físico como lógico.

Los intereses resguardados al diseñar, negociar, pactar y aplicar un contrato de Escrow se orientan a la protección del usuario final del intangible, es decir del software licenciado, para efectos de supuesto materia de análisis, el caso del empresario que adquiere un software para la producción de sus bienes o la prestación de los servicios. De surgir incovenientes con la utilización del software y de no existir proveedor para la prestación de servicios de actualización y vigencia del software el usuario final adquiere el derecho de acceder al Código Fuente para lograr la continuidad de la producción de bienes o la prestación de sus servicios.

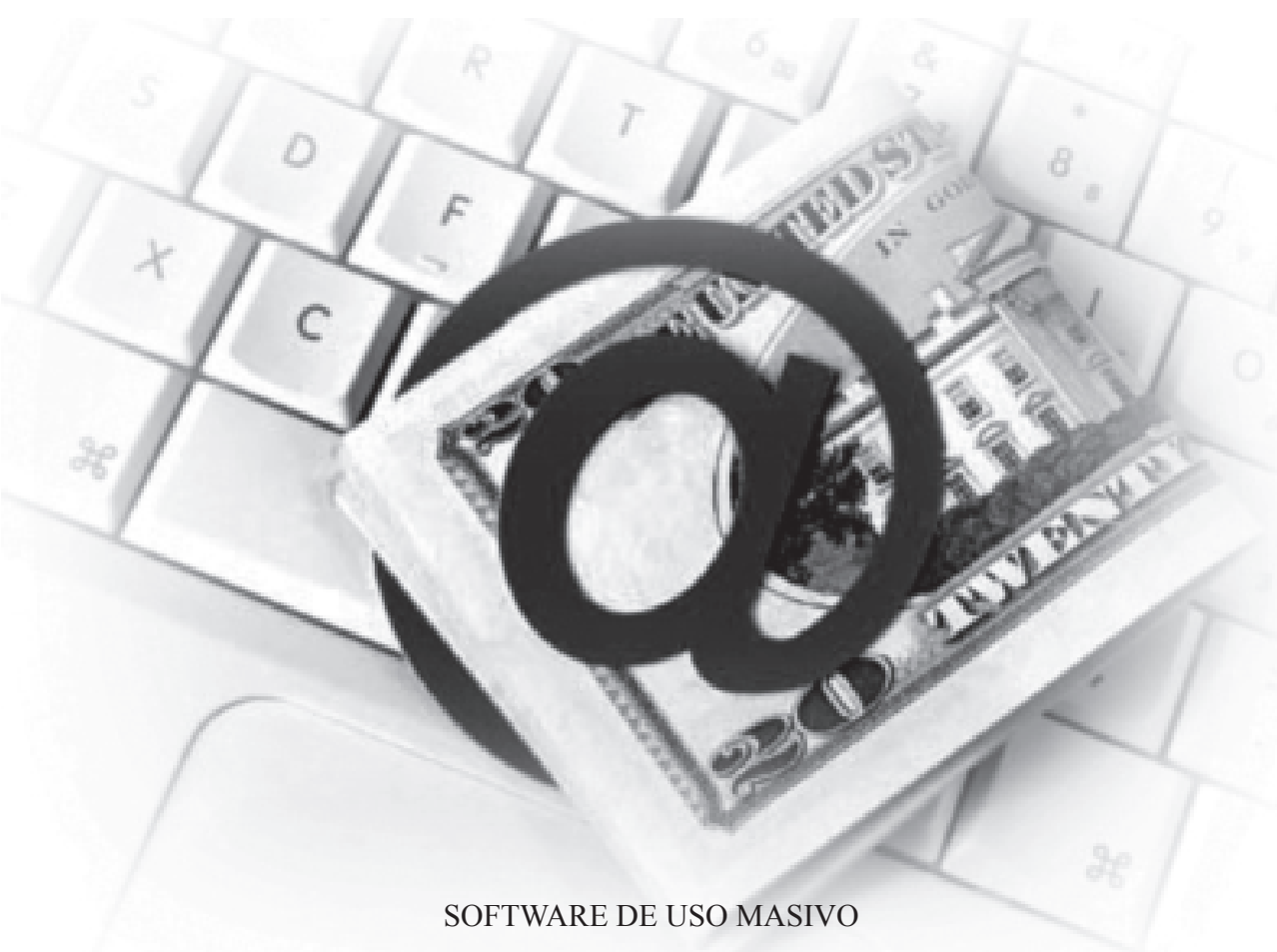

5 El Término escrow proveniente del idioma inglés, significa “(...) escritura entregada a tercero en depósito". Mayores referencias ver: MARTÍNEZ BARBEITO, Josefina y Julio G. Villalón. Diccionario técnico inglés español económico-financieroactuarial. La Coruña. Netbiblo S.L. 2003 p. 299. 
Por su naturaleza, el contrato de Escrow se caracteriza por ser flexible por cuanto permite proceder periódicamente a la actualización del Código Fuente depositada ante el tercero, con lo cual se garantiza que frente a cualquier problema con el proveedor del software siempre se tenga la última versión deposita para su posible uso, con lo cual el contrato de Escrow genera una potencialidad de aplicación importante al asegurar por todos los medios posibles la continuidad del servicio por parte del adquirente del software, con lo cual apreciamos que la lógica del contrato de Escrow está en íntima sintonía con la prestación de servicios por medios electrónicos, donde uno de los requisitos fundamentales, básicos y necesarios se encuentran centrados en la prestación de servicios a toda hora del día (mañana, tarde y noche), es decir, todos los días de la semana, todos los días del mes y todos los días del año.

Como podemos apreciar, el Derecho Informático nos presenta una modalidad contractual denominada Contrato de Escrow, cuya característica principal es que los conceptos jurídico informáticos son su base fundamental para la protección y aseguramiento del acceso al Código Fuente de los titulares con derechos de uso sobre determinado software aplicativo, normalmente desarrollado a medida; generándose de esta forma un contrato moderno y por lo tanto un documento jurídico valioso para la vida empresarial exitosa en su cotidiano accionar por medios informáticos.

\section{BIBLIOGRAFÍA}

ARIAS POU, María. Manual Práctico de Comercio Electrónico. Madrid. La Ley. 2006. 1100 p.

CODIGO CIVIL. Decreto Legislativo. 295. 1984.

ESPINOZA CÉSPEDES, José Francisco. Derecho Informático, Contratación Electrónica y Medidas de Seguridad. Lima. RAO. 2000. 375 p.

MARTÍNEZ BARBEITO, Josefina y Julio G. Villalón. Diccionario técnico inglés español económico-financiero-actuarial. La Coruña. Netbiblo S.L. 2003. 862. p. 
